\title{
ILMU BALAGHAH SEBAGAI EMBRIO DALAM DUNIA DAKWAH
}

\author{
Oleh A. Fajar Awaluddin
}

\begin{abstract}
Da'wah is a form of religious communication whose main purpose is amar ma'ruf and nahi munkar with object of da'wah, mad'u, either in the form of individual or group. Da'i as da'wah perpetrators are required to master the da'wah material to be submitted to mad'unya, which includes the problem of aqidah, shariah, muamalah, and morality. As for the source of da'wah material that is the Qur'an and hadith which is the source of the highest teachings and sources of Islamic law. The existence of Arabic in da'wah becomes so important because the two material sources of the da'wah use Arabic, so Arabic is the key to the opening of Islamic knowledge. To examine and depth it also requires mastery of various branches of science such as Science Tafsir, Nahwu Science, Bayan Science, Ushul Fiqih, etc., which is not far from Arabic. In addition, the original literary books which are the product of thought, interpretation, syarahan of the Qur'an and hadith by the scholars of the past written in Arabic, all of which are part of the source of da'wah material that should be known by the da " $i$. All that aims for the delivery of da'wah material sourced from the Qur'an and hadith in accordance with Islamic Shari'a and distanced from misunderstanding of understanding received by the mad'u in receiving messages conveyed by a da'i.
\end{abstract}

Kata Kunci: Islam, Qur'an, Balghah and Da'wah

\section{Pendahuluan}

Sebagai salah satu kajian dari ilmu Balaghah, Ilmu Ma'âni merupakan dasar-dasar dan kaidah-kaidah yang menjelaskan pola kalimat berbahasa Arab agar bisa disesuaikan dengan kondisi dan tujuan yang dikehendaki penutur. Tujuan 'ilmu alma'âni adalah menghindari kesalahan dalam pemaknaan yang dikehendaki penutur yang disampaikan kepada lawan tutur. Ilmuan bahasa yang dianggap sebagai pencetus Ilmu Bayan adalah 'Abdul Qâhir al-Jurjani ( w. $471 \mathrm{H}$ ). Dari terminologi 'ilmu al-ma'âni yang ingin menyelaraskan antara teks dan konteks, maka obyek kajiannya-pun berkisar pada pola-pola kalimat berbahasa arab dilihat dari pernyataan makna dasar - ashly, bukan tab'iy - yang dikehendaki oleh penutur. Menurut asSakkâki, yang dikehendaki oleh pembacaan model ma'âni bukan pada struktur kalimat itu sendiri, akan tetapi terdapat pada "makna" yang terkandung dalam sebuah tuturan. Jadi yang terpenting dalam pembacaan ma'ani adalah pemahaman pendengar terhadap tuturan penutur dengan pemahaman yang benar, bukan pada tuturan itu secara otonom. 
Syaiful Bahri Djamarah mengatakan bahwa balaghah sebagai cabang ilmu bahasa merupakan sarana yang efektif untuk menjalin komunikasi sosial. Tanpa bahasa, komunikasi tidak akan dapat dilakukan dengan baik dan interaksi sosial pun tidak akan pernah terjadi, karena hanya dengan bahasa seseorang dapat menyampaikan maksudnya kepada orang lain.

Bahasa Arab yang di dalamnya meliputi ilmu balaghah sebagai media dalam berkomunikasi merupakan bahasa yang digunakan oleh banyak kelompok manusia dan menjadi salah satu bahasa mayor di dunia. (Sabah Ghazzawi, 1992:1) yang saat ini digunakan oleh hampir seluruh belahan dunia, baik itu penutur asli dalam hal ini belahan dunia timur khususnya negara-negara Arab dan Afrika, maupun yang bukan penutur asli. Bahasa Arab sudah menjadi bahasa dunia internasional yang digunakan dalam forum resmi dunia seperti, PBB, OKI, dan Liga Arab.

Sejak keindahan kesusastraan ilmu balaghah yang tertuang di dalam Alquran didengungkan hingga kini, semua pengamat baik dari dunia Arab maupun dari barat menganggapnya sebagai bahasa yang memiliki standar ketinggian dan keelokan linguistik tertinggi yang tiada taranya. Ali al-Najjar dalam Syahin mengungkapkan bahwa ilmu balaghah yang merupakan cabang bahasa Arab merupakan bahasa yang terluas dan terkaya kandungannya, deskripsi dan pemaparannya sangat detail.

Selanjutnya Akkawi menulis bahwa Amir al-Mu'minin Umar bin alKhattab r.a. berkata: hendaklah kamu sekalian tamak mempelajari bahasa Arab karena bahasa Arab itu merupakan bahagian dari agamamu. Atas dasar ini pula lah Abdul Alim Ibrahim (1978:48) berkata bahwa bahasa Arab termasuk balaghah merupakan bahasa orang Arab dan sekaligus juga merupakan bahasa agama Islam.

Aktivitas dakwah merupakan suatu kegiatan komunikasi yang inti tujuannya adalah mempengaruhi orang lain ke arah yang baik. Setiap individu muslim dianggap sebagai komunikator agama atau da ${ }^{e e} i$ dimana diwajibkan menyampaikan ajaran agama sesuai kadar kemampuan masing-masing individu. Tanggung jawab ini menjadi suatu tugas yang penting, sehingga Rasulullah SAW dalam salah satu haditsnya yang sangat populer mengatakan yaitu," اوغ لب دـ نع و ول ثي أ " menuntut setiap muslim menyampaikan sesuatu darinya walaupun hanya "satu ayat". Simbolik walau hanya satu ayat menunjukkan pentingnya kebenaran ajaran agama disampaikan dengan baik.

Pesan dakwah yang disampaikan oleh setiap individu tentu saja membutuhkan dalil-dalil nash yang mendukung dan menjadi penguat sehingga apa yang disampaikan oleh seorang da ${ }^{\text {eci }}$ kepada pendengarnya atau mad'u menjadi lebih meyakinkan. Dalil- dalil nash tersebut adalah Alquran dan hadis yang jika ingin dikaji dan dipahami harus menggunakan bahasa Arab kajian ilmu balaghah. Sehingga ilmu balaghah dan dakwah merupakan suatu hal yang tidak bisa dipisahkan karena keduanya merupakan sendi agama Islam. Adanya hubungan antara kedua hal tersebut melatarbelakangi penulisan makalah ini. 
Adapun yang menjadi pokok pembahasan dalam makalah ini yaitu, eksistensi ilmu balaghah dalam Islam, ilmu balaghah sebagai salah satu kajian bahasa Alquran, dan posisi ilmu balaghah dalam dakwah.

\section{Pembahasan}

1. Ilmu Balaghah dan Islam

Pada awalnya struktur ilmu balaghah belumlah lengkap seperti yang kita kenal sekarang. Setelah mengalami berbagai fase perkembangan dan penyempurnaan akhirnya disepakati bahwa ilmu ini membahas tiga kajian utama, yaitu ilmu bayan, ma'ani dan badi'. Dalam hal ini pemakalah lebih menjelaskan ilmu ma'ani karena ilmu tersebutlah yang menjadi fokus kami di perkuliahan semester sekarang ini. Secara umum, sebenarnya tujuan ketiga cabang dari Ilmu Balaghah ini sama, yaitu bagamana cara mengungkapkan sesuatu yang indah dengan cara yang indah pula.

(a). Ilmu Balaghah Pra Islam

Orang-orang Arab Jahiliyah pra turunnya Al-Qur'an telah dikenal sebagai ahli sastra yang kompeten. Mereka mampu menggubah lirik-lirik sya'ir atau bait-bait puisi yang mempesona yang menunjukkan kesadaran dan keahlian mereka dalam bidang sastra yang bernilai tinggikehidupan orang Arab sebelum pra turunnya Al-Qur'an mempunyai karakter yang erat berkaitan dengan bahasa dan keindahannya, kehidupan mereka yang selalu dilandasi atas dasar membanggakan keturunan, dudukan, bahasa, dan lain-lainya mempunyai efek terhadap bahasa, di mana disaat mereka membanggakan bahasanya. Kelahiran dan pertumbuhan Balaghah (termasuk Ilmu Ma'ani) dikalangan masyarakat penggunanya bersifat arbitrer

Hal ini berarti bahwa orang Arab tidak hanya membanggakan begitu saja terhadap bahasanya, tetapi mereka juga berusaha agar yang mereka bangga-banggakan betulbetul berkualitas sehingga tidak dapat dikalahkan oleh yang lainnya. Kompetisi ini secara langsung berimbas pada keindahan bahasa dan fashohahnya, yang menunjukan bahwa mereka sudah mengenal Al-Balaghah al-kalam. Buktiyang menunjukan bahwa masyarakat Arab sudah mengenal dan menguasai al-balaghah adalah mu'jizat Rasul yang menantang mereka untuk membuat yang serupa dengan fashohah dan balaghoh al-Qur'an dengan gaya bahasanya yang sangat tinggi. Walaupun mereka tidak mampu, namun tantangan ini merupakan bukti bahwa mereka mempunyai kemampuan untuk membuat ibaraat dengan gaya bahasa dan fashahah yang tinggi.

Diriwayatkan bahwa Al-Walid bin Al-Mughirah salah seorang musuh bebuyutan Rasulullah saw mendengan ayat-ayat al-Qur'an yang dibacakan Rasulullah SAW, kemudian ia berkata:

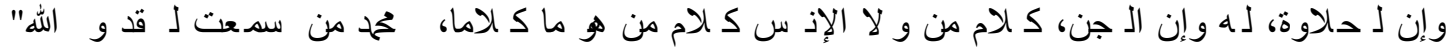

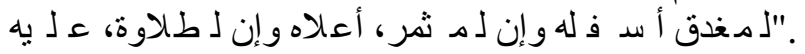

Artinya: "Demi Allah saya telah mendengar sebuah kalam (ayat al-Quran) dari Muhammad, ungkapannya bukanlah ungkapan manusia taupun jin, sesungguhnya ungkapan tersebut sangat bagus dan indah, permulaannya sangat berisi dan lebih lagi di penutupnya". 
Kekaguman al-Walid ini menunjukan bahwa masyarakat Arab telah mengenal akan fashohah dan balaghoh dalam sebuah ungkapan dan mempu untuk menilainya dengan objektif. Al-Balaghah pada zaman Jahiliyah belum dikenal sebagai sebuah disiplin ilmu yang sudah matang dan mempunyai mustholahat yang terdefinisi dengan jelas. Dalam karya-karya mereka sangat banyak ditemukan akan balignya (indah dan tingginya) ungkapan mereka, secara teoritis Al-Balaghah belum dikenal, tetapi sudah dipraktekkan dan diterapkan dalam karya-karya mereka baik berupa syi'ir maupun natsr.

(b). Ilmu Balagah Pasca Islam

Sebagaimana dilihat sebelumnya bahwa keberadaan Balaghah pasca turunnya alQur'an sudah demikian berkembang, lebih-lebih setelah turunnya al-Qur'an. Keindahan dan kelembutan berbahasa merupakan pokok kajian yang tak habishabisnya, yang telah melahirkan banyak ungkapan-ungkapan yang indah dan bermakna dalam kepustakaan sastra, terutama setelah turunnya al-Qur'an yang merupakan salah satu inspirator dalam melahirkan keindahan dan kelembutan berbahasa tersebut.

Dalam tradisi Islam, al-Qur'an dipandang sebagai salah satu sumber keindahan atau ke-balaghah-an bagi para penyair dan penulis prosa. Al-Qur'an, diakui oleh mereka sebagai puncak balagah dan merupakan model utama dalam rujukan penggubahan syai'r.

Sebagian pakar sastra mencoba dengan sadar dan seksama untuk menyamai bahkan melampaui keindahan al-Qur'an. Upaya-upaya tersebut mereka lakukan untuk meladeni tantangan al-Qur'an yang begitu menggugah orang-orang yang memiliki keahlian dan keberanian di antara mereka, meski usaha tersebut tidak pernah berhasil. Tantangan al-Qur'an itu semakin menarik perhatian mereka disamping telah adanya rasa cinta terhadap keindahan dan ketinggian bahasa yang melekat kuat dalam jiwa mereka sejak masa pra turunnya al-Qur'an.

Sampai masa permulaan Islam ini keberadaan ilmu Balaghah sebagai suatu disiplin ilmu yang utuh seperti saat ini belum terkodifikasi, namun ia terus mengalami perkembangan sedikit demi sedikit. Diawali dengan kajian sastra terhadap beberapa sya'ir dan pidato-pidato orang Jahiliah, dilanjutkan dengan mengulas sya'ir dan sastra pada masa awal Islam, sampai kepada masa pemerintahan Daulah Umaiyah, ia terus mengalami perkembangan yang menggembirakan.

Kitab yang pertama kali disusun dalam bidang balaghah adalah tentang ilmu bayan, yaitu kitab Majazul Qur'an karangan Abu 'Ubaidah Ma'mar bin Al-Mutsanna (w. 208), murid Al-Khalil (w. 170 H).Sedangkan ilmu ma'ani, maka tidak diketahui pasti orang pertama kali yang menyusun tentang ilmu tersebut. demikian, tidaklah salah jika ada yang mengatakan bahwa bahasa Arab yang di dalamnya mengandung kesusastraan balaghah adalah bahasa agama Islam.

Dari pemaparan di atas, nampak jelas bahwa eksistensi ilmu Balaghah yang bagian bahasa Arab dalam dunia Islam begitu penting karena ilmu tersebut merupakan bahasa kunci ajaran-ajaran Islam yang tertuang dalam Alquran, hadis, dan kitab-kitab tafsir, dan syarah hadis. Selain itu bahasa Arab juga menjadi bahasa kunci pembuka 
khasanah ilmu pengetahuan agama dan sains yang sumber utamanya terdapat dalam kitab-kitab berbahasa Arab yang banyak dikaji oleh para ilmuwan barat.

2. Ilmu Balaghah dan Alquran

Sebagai mu'jizat, al-Qur'an merupakan kitab yang memiliki susunan kalimat yang indah, tertip dan rapih. Untuk memahami kei'jaz-an bahasanya tentu dibutuhkan penguasaan bahasa yang Arab yang mendalam. Salah satu cabang ilmu yang mempelajari hal tersebut yaitu ilmu Balaghah. Dalam berbagai literatur disebutkan bahwa disiplin ilmu ini merupakan salah satu cabang ilmu pengetahuan yang menjadi alat untuk menguak kemukjizatan al-Qur'an. Posisinya dalam tatanan kelompok ilmu-ilmu Arab persis seperti posisi ruh dari jasad. Dengan kata lain, ilmu ini merupakan media yang dapat menghantarkan seseorang memahami ke-i'jaz-an alQur'an. Struktur bahasa al-quran adalah salah satu dari sekian banyak ciri khas gaya Al-Quran yang membuat bangsa Arab tidak mampu meniru dan menyainginya. Kalimat terdiri dari tiga unsur: Huruf-huruf yang berasal dari sekumpulan bunyi,katakata yang tersusun dari huruf-huruf,dan kalimat yang tersusun dari kata-kata. Issa j. Boullata menekankan bahwa rahasia mukjizat al-Qur'an mencakup ketiga unsur tersebut.

Bahasa yang terdapat di dalam Al-Qur'an tidak dapat terkalahkan bahkan oleh ahli retorika bangsa Arab sekalipun. Ketika dibacakan al-Qur'an kepada mereka, mereka mendapatkan huruf-huruf yang ada dalam kata-katanya dan kata-kata yang ada dalam kalimat-kalimatnya dalam wujud lagu bahasa yang sangat indah. Karena keserasian dan kekompakannya, bagaikan sepenggal lagu sementara pembacanya adalah pelantunnya. Pada saat itu juga, mereka menyadari bahwa manusia mempunyai keterbatasan yang sangat terhadap bahasa itu. Salah seorang dari mereka yang berusaha menyaingi al-Qur'an,seperti Musailamah al-Kadzdzab,memilih untuk merangkai apa yang disangkanya jalinan musikal atau bagian dari hal itu, dan mengesampingkan eksploitasi bahasa,gaya,seni keindahan,dan seluk-beluk konstruksi susatra.

Struktur musical yang ada dalam al-qur'an memperlihatkan suatu konsep yang tinggi, ke-balaghah-an yang menjadi mukjizatnya secara alami. Bahasanya dalam rangkaian huruf-huruf yang dibuat dengan mempertimbangkan bunyi,makhraj,dan keserasian antara satu huruf dengan huruf lainnya secara alami dalam hams(bisik), jahr(terang), syiddah(kencang), rakhawah (longgar), tafkhim(tebal), tarqiq(tipis).

Kata dan Huruf

Salah satu prinsip dasar dalam struktur al-Qur'an adalah dipertimbangkannya huruf sesuai dengan bunyi,harakat, dan kedudukannya terhadap makna. Oleh karenanya tidak mungkin mengandung sesuatu yang bisa dikatakan sebagai huruf tambahan, huruf tak beraturan,frasa sisipan,atau apa yang bisa disebut dengan masa jeda, sebagaimana ditemukan dalam gaya bahasa para pujangga. Kalimat adalah ekspresi dari perkataan,juga gambaran psikologis dari komposisi alamiah. Dengan kalimat, manusia mengubah materi yang ada di alam menjadi makna yang 
dilukiskannya di dalam dirinya, hingga jiwa pun bisa melihat dan merasakan materi yang terlukiskan itu, sementara,bisa jadi tidak terlihat oleh pembicara yang memberinya tujuan tertentu dalam pembicaraan.

Gaya bahasa al-Qur'an yang mengandung mukjizat itu adalah sebab utama kelestarian bahasa Arab dan penggalian ilmu-ilmunya. Asal-muasalnya ialah dari tantangan. Hikmah dari tantangan itu adalah timbulnya dorongan untuk untuk meneliti gaya bahasa dan strukturnya,merenungkan metodenya, menyatakannya sendiri dan menimbangnya,hingga ketika mereka yakin benar-benar tidak mampu, tergugahlah orang-orang yang datang kemudian untuk memahami segi-segi kemukjizatan, dari sini seni-seni retorika tersingkap, dan mereka pun mulai giat meneliti bahasa arab dan menyingkapkan keindahan-keindahannya.

Dari sisni, seni-seni retorika tersingkap, dan mereka pun mulai giat meneliti bahasa arab dan menyingkapnya keindahan-keindahanya. Masing-masing saling meragsang dan saling mendukung, hingga seluruh materinya terkumpul dan semua unsurnya tersusun. Kalau bukan karena apa yang mereka kerjakan itu, tentu orangorang arab sudah berubah menjadi Ajam (non-Arab), warisan susastra ini sudah hilang, dan tidak akan ada orang di muka bumi ini yang mengatkan Al-Qur'an mengandung mukjizat.

3. Ilmu Balaghah Sebagai Embrio Dalam Dunia Dakwah

Dakwah merupakan salah satu bentuk komunikasi dan seluruh agama disebarluaskan melalui proses komunikasi. Tanpa adanya komunikasi agama tidak mungkin bisa berkembang di dunia ini. Hal ini berlaku bagi semua agama di dunia, tak terkecuali agama Islam. Proses komunikasi dalam penyebaran agama Islam diistilahkan dengan dakwah.

Dakwah adalah suatu kajian dalam seruan, baik dengan lisan, tulisan, atau tingkah laku yang dilakukan secara sadar dan berencana untuk mempengaruhi orang lain agar timbul suatu pengertian, kesadaran, penghayatan, serta pengalaman ajaran agama tanpa adanya unsur paksaan (M. Arifin, 1993:6). Dakwah merupakan upaya untuk menumbuhkan kecenderungan dan ketertarikan dan tidak hanya terbatas pada aktivitas lisan semata akan tetapi mencakup seluruh aktivitas lisan maupun perbuatan yang ditunjukkan dalam rangka menunbuhkan kecenderungan dan ketertarikan dalam Islam. Artinya tujuan dakwah adalah bagaimana mengajak orang lain agar senantiasa mengamalkan apa yang diperintahkan oleh Allah SWT yang timbul dari kemauan mereka sendiri (Ahmad Mubarak, 2002:13).

Keberhasilan dakwah sangat bergantung pada kedekatan juru dakwah dengan umatnya. Juru dakwah yang terlahir pada suatu lingkungan pasti akan memahami lorong-lorong kesesatan yang membungkus masyarakat di lingkungan tersebut.

Selain pengetahuan yang dalam mengenai kondisi dari lingkungannya, juru dakwah juga harus bisa berkomunikasi dengan masyarakatnya dengan baik. Tentunya yang dibutuhkan oleh juru dakwah adalah penguasaan bahasa yang digunakan untuk komunikasi sehari-hari. Adapun unsur-unsur dakwah meliputi: da ${ }^{e e}$, mad ${ }^{\text {ee }} \mathrm{u}$, dan materi dakwah. 
a. Da"i secara bahasa berasal dari bahasa Arab, bentuk isim fa'il dari da'a, yad'u, da'watan yang berarti orang yang melakukan dakwah. Secara terminologi, da ${ }^{\text {ee }}$ berarti setiap muslim yang mukallaf (aqi bhalig) dengan kewajiban dakwah (Idris A Shomad, 2004:6). Seorang da ${ }^{e i}$ tidak hanya harus mengetahui dan hafal berbagai macam ayat dan hadis melainkan seorang da"i dituntut harus menguasai ajaranajaran Islam. Penuh kewibawaan dan wawasan yang tinggi karena selayaknya da ${ }^{e c} i$ memahami berbagai aspek sendi kehidupan.

b. Mad'u yaitu manusia yang menjadi sasaran dakwah, atau manusia penerima dakwah, baik individu maupun kelompok, baik beragama Islam maupun tidak, atau dengan kata lain, manusia secara keseluruhan (M. Munir dan Wahyu Ilahi:23). Mad'u juga dapat diartikan objek dakwah yang sedang dilakukan oleh seorang da ${ }^{e e} i$.

c. Maddah atau materi dakwah adalah masalah isi pesan atau materi yang disampaiakan oleh da'i kepada mad'u yang bersumber dari Alquran dan hadis yang meliputi aqidah,syariah dan akhlaq (Nurul Badrutamam, 2005:109). Yang perlu dipahami bahwa dakwah bukan hanya berkaitan dengan eksistensi dan wujud Allah, akan tetapi lebih dari itu, bagaimana memberikan kesadaran yang dalam agar mad'u dapat mengaktualisasikan aqidah, syariah dan akhlaq dalam kehidupan sehari-hari.

Seorang daeei harus mampu membaca kondisi dan situasi mad'u agar materi yang diisampaikan mudah dipahami dan dilakksanakan oleh mad'u. Disinilah peran maddah atau materi sangat diutuhkan guna menunjang keberhasilan dalam berdakwah.

Adapun menurut M.Munir dan Wahyu, secara umum materi dakwah dapat diklasifikasikan menjadi empat masalah pokok, yaitu: 1) Masalah aqidah islamiyah atau keimanan. Aspek aqidah ini membentuk moral manusia. Karena aqidah bersifat sentral pada diri manusia dan sangat erat hubungannya dengan rukun iman. 2) Masalah syariah dan hukum. Hukum dan syariah disebut sebagai cermin peradaban. Materi dakwah yang meyajikan unsur syariah harus dapat menggambarkan atau memberikan informasi yang jelas di bidang hukum dalam bentuk status hukum yang bersifat wajib, mubah, makruh, dan haram. 3) Masalah muamalah. Islam merupakan agama yang melakukan urusan muamalah yang lebih besar porsinya dari urusan ibadah. Islam lebih banyak memperhatikan aspek kehidupan sosial daripada aspek kehidupan ritual. 4) Masalah akhlaq. Islam mengajarkan manusia berbuat baik dengan ukuran yang bersumber dari Allah. Sebagaimana telah diaktualisasikan oleh rasulullah SAW. Apa yang digariskan baik oleh-Nya dapat dipastikan baik secara esensial oleh akal pikiran manusia. Dalam Alquran dikemukakan bahwa kriteria baik itu antara lan bertumpu pada sifatsifat Allah SWT. (M.Munir dan Wahyu Ilahi: 24-30)

Keberadaan ilmu Balaghah dalam dunia dakwah dapat dilihat dari sisi materi dakwah itu sendiri. Tentu saja ketika seorang dae I ingin menyampaikan suatu pesan keislaman yang menjadi materi dakwah harus lebih dahulu menguasai materi tersebut yang berasalkan dari Alquran maupun hadis yang berbahasakan bahasa Arab. Itu tentu saja seorang da ${ }^{e i}$ harus menguasai terlebih dahulu bahasa Arab dan segala permasalahannya. 
Seperti contoh, dalam mempelajari atau mendalami materi dakwah yang bersumberkan dari Alquran seorang da ${ }^{\text {ec }}$ diharuskan menguasai metode - metode mempelajari ayat-ayat Alquran seperti Ilmu Tafsir, Ilmu Nahwu, Ilmu Balaghah, Ushul Fiqih, dll., yang semua itu tidak terlepas dari bahasa Arab. Belum lagi adanya istilah-istilah keislaman yang tak jauh dari bahasa Arab. Dan kurang lebih seperti itu juga ketika seorang da eei ingin mempelajari hadis-hadis atau sunnah Rasulullah sebagai sumber dari materi dakwah.

Semua itu bertujuan agar dalam penyampaian materi dakwah yang bersumber dari Alquran maupun hadis sesuai dengan syariat Islam dan menjauhkan dari kesalahpahaman pemahaman yang diterima si Mad'u dalam menerima pesan-pesan yang disampaikan oleh seorang da ${ }^{e e} i$.

Ilmu Balaghah pun dapat menjadi seni ketika seorang da ${ }^{\text {ee }} i$ dalam menyampaikan pesan-pesan ke- Islamannya. Kredibilitas tidak tumbuh dengan sendirinya ia harus dibina atau dipupuk. Kredibilitas erat kaitannya dengan kharisma, dengan demikian kredibilitas dapat ditingkatkan sampai batas optimal. Untuk mendapatkannya tersebut salah satu yang harus dimiliki seorang da $i$ adalah kemampuan menguasai bahasa, dan salah satu nya adalah bahasa Arab dan Ilmu Balaghah. Untuk memudahkan penyampaian dan memperindah retorika saat menyampaikan pesan- pesan keislaman.

\section{Kesimpulan}

Untuk menyimpulkan uraian tentang eksistensi Ilmu Balaghah dalam dunia dakwah maka dapat dikemukakan hal-hal sebagai berikut:

1. Ilmu Balaghah secara kenyataan bukanlah bahasa khusus orang-orang muslim dan bukan satu-satunya bahasa agama Islam, tetapi Ilmu Balaghah adalah bahasa yang paling dominan digunakan dalam Islam karena kaitannya dengan keberadaan Muhammad sebagai orang Arab dan Alquran yang diturunkan dalam bahasa Arab.

2. Ilmu Balaghah adalah salah satu unsur kajian bahasa Alquran yang merupakan kitab suci agama Islam, dan merupakan sumber ajaran dan hukum Islam. Untuk memahami dan mengkaji isi dan kandungan Alquran dibutuhkan berbagai macam ilmu-ilmu yang berhubungan dengannya, seperti berbagai cabang ilmu tafsir, ushul fiqh, Nahwu, Balaghah, dll., yang kesemuanya itu tidak terlepas dari bahasa Arab.

3. Sementara dakwah merupakan salah satu bentuk komunikasi, dan seluruh agama disebarluaskan melalui komunikasi. Tujuan dakwah yaitu mengajak manusia ke jalan Allah SWT, jalan yang benar dan mengamalkan ajaran-ajaran Islam yang bersumber dari Alquran dan hadis. Keduanya merupakan sumber materi dakwah dan yang dapat dengan mudah dipahami dan dikaji dengan menggunakan kajian Ilmu Balaghah. 


\section{Daftar Pustaka}

Abu Zaid Nasr Hamid. 2002. Tekstualitas Alquran. Ed. Revisi; Yogyakarta: LkiS. Asy ${ }^{\text {ee } a r i y, ~ H a s y i m . ~ 1999 . ~ B a h a s a ~ A r a b ~ d a n ~ p e r k e m b a n g a n ~ i l m u ~ p e n g e t a h u a n, ~ J u r n a l ~}$ Nadi. Edisi September, Malang.

Taufiq, Muhammad Syahin. 1980. Awaamil Tanmiyyah al-Lugah alA'rabiyyah. Al-Qaahirah. Mathbae al- Da" wah al-Islamiyyah.

Arifin, M. 1993. Psikologi Dakwah Suatu Pengantar Studi. Jakarta: Bumi Aksara.

A Shomad, Idris. 2004. Diktat Ilmu Dakwah. UIN Syarif Hidayatullah, Fakultas Dakwah dan Komunikasi: Jakarta.

Ash-Shiddiqi, Hasbi. 1975. Falsafah Hukum Islam. Jakarta. Bulan Bintang.

Aliyudin. Dasar-Dasar lmu Dakwah. Fakultas Dakwah Dan Komunikasi Uin Sgd Bandung.

Arsyad, Azhar. 2004. Bahasa Arab dan Metode Pengajarannya. Cet.II; Pustaka Pelajar: Yogyakarta. Kitab Tafsir Alquran Al-'Azhim, Ibnu Katsir, Jilid 2.

Atang Abd. Hakim dan Jauhari Mubarak. 2008. Metodologi Studi Islam. Bandung: Rosdakarya.

Badrutamam, Nurul. 2005. Dakwah Kolaboratif Tarmizi Taher. Jakarta: Grafindo. Djamarah, Syaiful Bahri. 2008. Psikologi Belajar. Cet. II; Jakarta: PT. Rineka Cipta.

Ghazzawi, Sabah. The Arabic language.Washington D.C. Center for Contemporary Arab Studies.

Izzan, Ahmad. 2007. Metodologi Pembelajaran Bahasa Arab. Cet.II; Bandung: Humaniora.

Jum $^{\text {ee }}$ ah, Amin Abdul Azis. 2010. Fiqh Dakwah (terj.). Era Intermedia. Solo.

M.Munir dan Wahyu Ilahi, Manajemen Dakwah. Cet. II; Jakarta: Kencana Prenada Media Group.

Mubarak, Ahmad. 2002. Dakwah Islam.Cet. I; Bogor: Thariqul Izzah.

Poeradisastra, S.I. 1981. Sumbangan Islam kepada Ilmu d an kebudayaan Modern. Jakarta: Girimukti Pasaka.

Rahmat, Jalaluddin. 1998. Retorika Modern Pendekatan Paraktis. Bandung: Remaja Rosdakarya.

al-,Uqail, Ahmad bin Abdul Wahhab. 2003. Qul Hadzihi Sabili Ad'u ila Allah ala Bashirah. Mesir. Dar al- Kutub.

Rahmat, Jalaluddin. 1998. Retorika Modern Pendekatan Paraktis. Bandung: Remaja Rosdakarya.

http://m.anwar-sanusi.abatasa.co.id 